\title{
An Approach to Estimation of Gas Reserve of Narshingdi Gas Field in Bangladesh with Dynamic Reservoir Simulation
}

\begin{abstract}
Farhana Akter
Petroleum \& Mineral Resources Engineering (PMRE), Bangladesh University of Engineering and Technology BUET, Dhaka-1000, Bangladesh

Abstract:

Increasing demand of fuel globally formulates gas as one of the most valuable natural resources. There is lot of uncertainties in estimating hydrocarbon volume correctly from exploration to development stage of a gas field. The accuracy and reliability of data (reservoir geological model, fluid and rock properties) make the implement very hard-hitting. So estimating and updating the gas reserve has become vital issue, as it helps the planners for drawing mid-term and long-term development plan from field development level to national level. This paper presents the study of reserve estimation of a Narshingdi Gas Field in Bangladesh. In this paper, a dynamic reservoir simulation model has been used to perform a history match "pressure and production" using commercial simulator for reserve estimation. The result of this study is expected to provide Gas Initially in Place (GIIP) and recoverable gas volume. Simultaneously three forecast scenarios have also been investigated. There is no strong aquifer pressure support in the producing gas zone, so gas production continues from the reservoir due to pressure depletion.
\end{abstract}

Key words: Gas Reserve Estimation, History Match, Forecasting.

\section{Introduction}

Narshingdi gas field is located in northeastern part of Bangladesh in the western edge of the eastern fold belt in the northern portion of Block 9. ${ }^{1}$ The Narshingdi Field is an anticline with a simple four-way dip closure at the northern end of the Bakhrabad-MeghnaNarshingdi structure trend and it lies on the southern fringes of the Surma Basin which is located at the western margin of the North-South trending Chittagong-Tripura folded belt. Narshingdi structure was identified by Pakistan Shell Oil Company (PSOC). ${ }^{1}$ Two commercial accumulations of gas sands named as lower gas sand (LGS) and upper gas sand (UGS) have been discovered in two different depositional environments. Production is continuing only from lower gas sand through two wells named NAR-1 and NAR-2 from $25^{\text {th }}$ July 1996 and $18^{\text {th }}$ February 2007 respectively. Table 1 and table 2 shown below gives the information about the wells and the reservoir respectively $.1,3,4$

Table-01: Well Summary

\begin{tabular}{lcc}
\hline \multicolumn{1}{c}{ Parameters } & \multicolumn{2}{c}{$\begin{array}{c}\text { cower Gas Sand } \\
\text { (LGS) }\end{array}$} \\
\hline Well Name & NAR-1 & NAR-2 \\
Well type & Vertical & Vertical \\
Well depth (m) & 3450 & 3285 \\
Initial production rate & 25 & 17 \\
(MMscfd) & & \\
Cum Prod. Up to Dec & 114.25 & 35.9655 \\
2013(BCF) & 4228 & 3233 \\
Initial Pressure (psia) & 205 & 163 \\
Initial Temperature ( $\left.{ }^{\circ} \mathrm{F}\right)$ & 3.5 & 4.5 \\
Tubing size (inch) & 3480 & 2857 \\
Shut in well head pressure & & \\
(psia) & 1443 & 1330 \\
Tubing head pressure in Dec. & & \\
2013(psia) & & \\
\hline
\end{tabular}

Table 02: Reservoir Parameters

\begin{tabular}{lc}
\hline Parameters & Values \\
\hline Rock compressibility $\left(\mathrm{psia}^{-1}\right)$ & $3 \times 10^{-6}$ at 3804 psia \\
specific gravity & 0.6 \\
condensate-gas-ratio (CGR) & $2.24 \mathrm{bbl} / \mathrm{MMscf}$ \\
water gas ration (WGR) & $1 \mathrm{bbl} / \mathrm{MMscf}$ \\
Minimum water saturation & 0.35 \\
\hline
\end{tabular}

The static geological grid model (used in this study) has a dimension of $101 \times 149 \times 29$ representing four sand layers of the field. It has been discretized into 328 x $328 \mathrm{ft}$ grid blocks. For simulating of gas water system the model grid layering was designed with average thickness of $10 \mathrm{ft}$. The total number of active grid blocks of 66,966 . Other properties of the grid model are shown in table $2 .^{6}$

Table-03: Properties of static geological grid model:

\begin{tabular}{|c|c|c|c|c|}
\hline $\begin{array}{l}\text { Sand } \\
\text { layer }\end{array}$ & $\begin{array}{l}\text { Porosity } \\
(\%)\end{array}$ & $\begin{array}{c}\text { Permea } \\
\text { bility } \\
(\mathrm{mD})\end{array}$ & $\begin{array}{c}\text { Thickne } \\
\text { SS } \\
(\mathbf{m}) \\
\end{array}$ & status \\
\hline UGS & $0.15-0.22$ & 77 & 9.5 & $\begin{array}{c}\text { Not } \\
\text { Producing }\end{array}$ \\
\hline MGS-1 & - & - & & Inactive \\
\hline MGS-2 & - & - & & Inactive \\
\hline LGS & $0.07-0.22$ & $1-100$ & 14 & Producing \\
\hline
\end{tabular}

The fluid from the lower gas sand of the Narshingdi Gas Field is non-retrograde at reservoir condition and can be defined as lean gas. The fluid contains over $97 \%$ methane and ethane. The gas properties were analyzed at the reservoir temperature of $205.8{ }^{\circ} \mathrm{F}$ and pressure range of $15-5000$ psia. 
Brooks-Corey's equations for two-phase flow have been used to generate relative permeability curves. The assumption 'fluid flow is neither segregated nor evenly distributed' gives Corey exponents of 4 for water and 2 for gas. Minimum water saturation is selected as the endpoint ${ }^{2}$.

To calculate well head pressure for history match and production forecast, vertical lift performance (VFP) curves have been generated by using commercial software for two wells NAR-1 and NAR-2. For pressure traverse calculation, Beggs and Brill flow correlations has been chosen because it performs well in gas and gas condensate well ${ }^{2}$. The minimum gas flow rate for continuous removal of liquid is approximately 4MMscfd and 5MMscfd for NAR-1 and NAR-2 respectively.

\section{History Matches}

In this section the simulation model has been applied to match production and pressure data obtained from history by manipulating permeability, porosity, fluid contact to confirm the initial reservoir conditions.

\subsection{Average Reservoir Pressure Match:}

For reservoir pressure match, the recorded shut in well head pressure was converted into shut in bottomhole pressure using the average temperature and $\mathrm{Z}$ factor method $^{2}$. After that an effort was taken to match with the simulated reservoir pressure and obtained a good match that is shown in Figure 1.

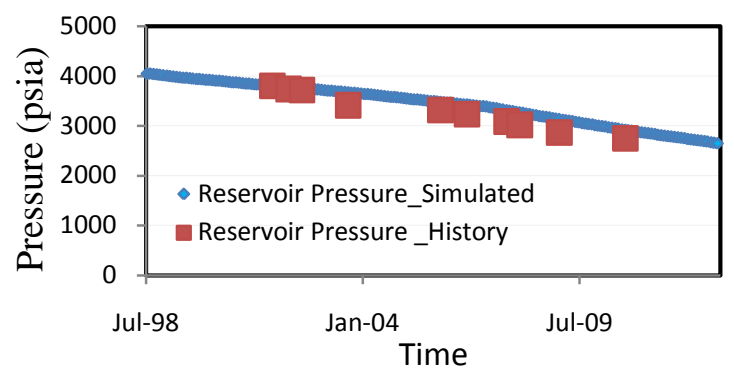

Figure 1: Average reservoir pressure match

\subsection{Tubing Head Pressure (THP) Match:}

In addition to, another attempt was taken to match THP for two wells (NAR-1 and NAR-2). Here both wells are controlled on the gas rate and the all historical tubing head pressure data have been introduced to the simulated tubing head pressure data. Though there is a slight difference between the simulated THP and historical THP in case of NAR-1 (Figure 2) and NAR2 (figure 3 ), but the overall match is satisfactory. In case NAR-1, there are some peak points in tubing head pressure.It may be for keeping the well shut down for development purpose and thereby pressure went up.

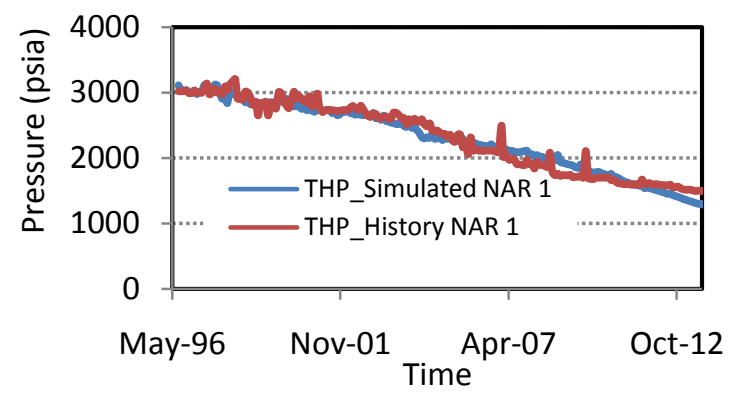

Figure 2: Tubing Head Pressure Match for well NAR-1

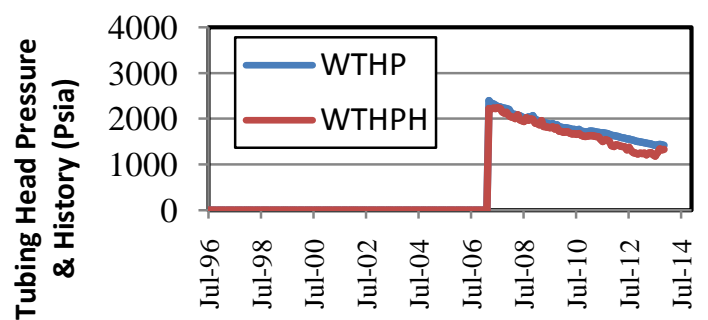

Time (Years)

Figure 3: Tubing Head Pressure Match for well NAR-2

After obtaining a good pressure match with recorded reservoir SIWHP and individual well's THP, it can be said that pressure history match validates the reservoir grid model satisfactorily.

\subsection{Simulation Result:}

The simulated result is shown in figure 4. GIIP for upper gas sand and lower gas sand are $83.53 \mathrm{Bcf}$ and 302.72 Bcf respectively. So the field total GIIP is $386.24 \mathrm{Bcf}$.

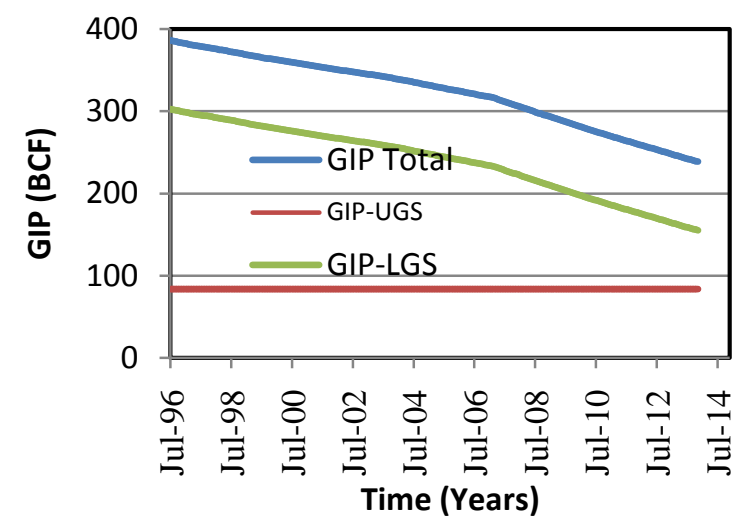

Figure 4: GIP vs Time plot

From figure 4, up to December 2013, 149 BCF gas from lower gas sand has been produced. GIIP of upper gas sand remained unchanged since this sand zone has not been under production. 


\section{Performance Projections}

Between two gas sands (upper and lower gas sands), only the lower gas sand has been developed. Two cases are considered to forecast the future performance of the LGS. The cases are-

3.1 Forecast case 1: Present condition that involves predicting future production with the existing wells until the economic rates of the wells are reached.

\subsection{Forecast case 2:}

Impact of additional well which is defined by drilling of a new vertical well to the lower gas sand to produce at a rate of 10 MMscfd from the January 2015 along with other two existing wells (NAR-1 and NAR-2) producing at a rate of 18 and 15 MMscfd accordingly.

\subsection{Forecast Case 3: Effect of using compressor}

This forecast case has been divided into two sub groups. In both two groups abandonment wellhead pressure is reduced from 1000 psia to 500 psia to show the effect of compressor on ultimate recovery.

Case 3a: Present condition

Case 3b: With one additional well

The economic limit: Constraint for the three wells is

NAR-1: 4 MMscfd,

NAR-2: 5 MMscfd,

NAR-3: 4 MMscfd

The abandonment tubing head pressure limit is 1000 psia.

\section{Result}

All the forecast cases are set up to run till December 2030 with the current well production capacity and continued till the economic limit is reached.

\subsection{Forecast case-01: Present Condition}

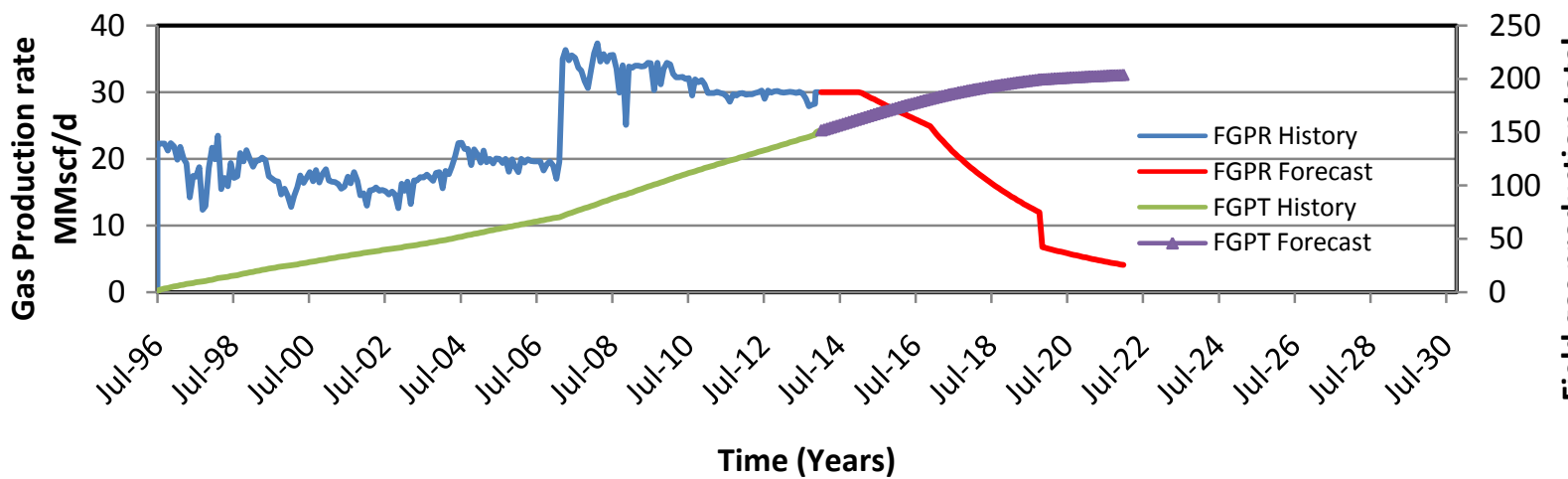

Figure 5: Forecasting of existing condition for THP 1000 psi.

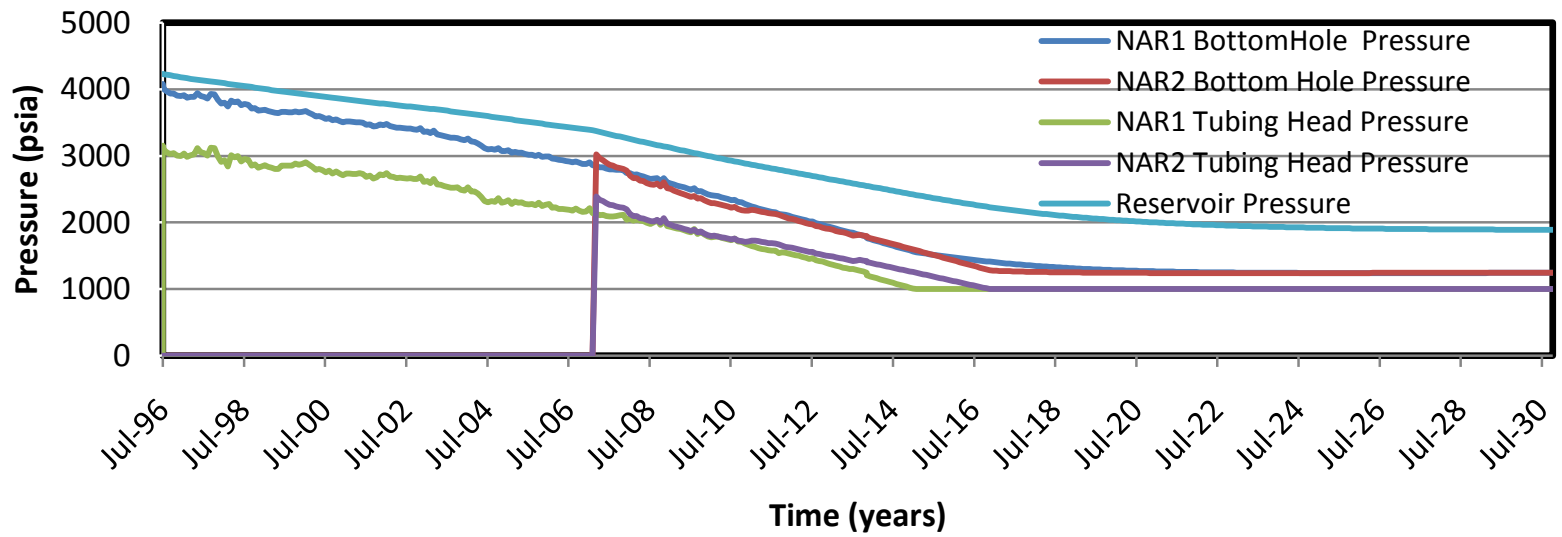

Figure 6: Pressure profile for existing condition.

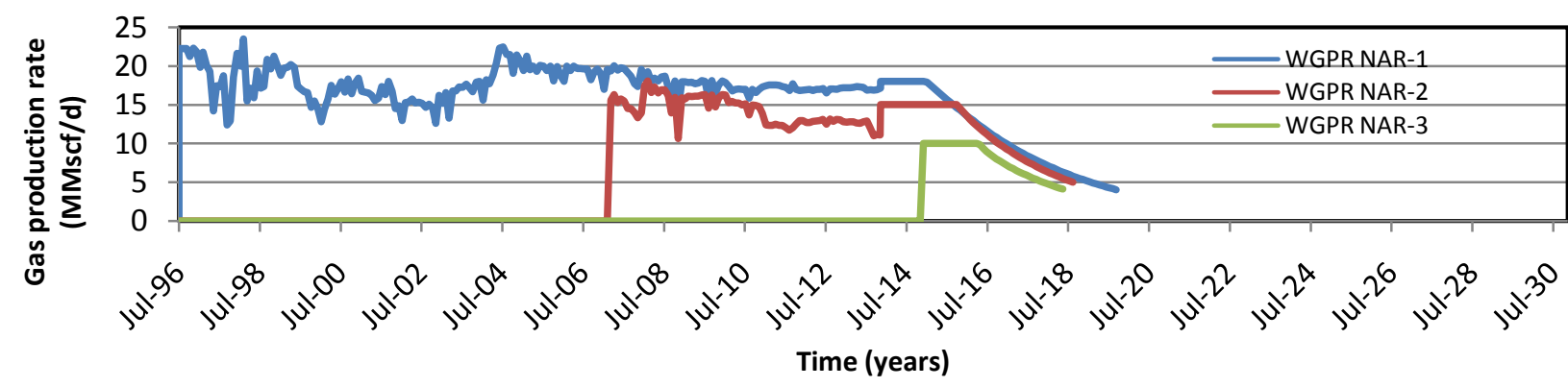

Figure 7: Impact of additional vertical well on well gas production rate 


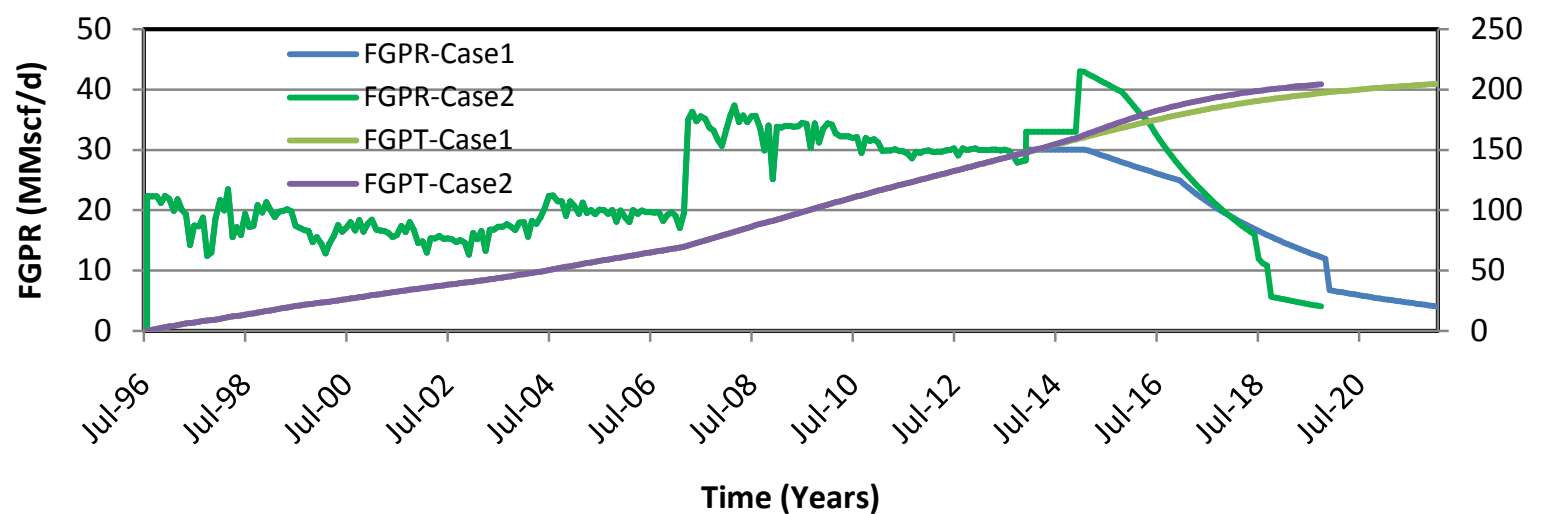

Figure 8: Forecasting of gas production when a vertical well is added.

From figure 5 it can be shown that production will be continued till January 2022 as the limiting constraints have been met. At that time field gas production total will be $204.022 \mathrm{Bcf}$.

The pressure profile plot shown in figure 6 shows that NAR-1 will produce up to January 2022 while due to low bottom hole flowing pressure, NAR-2 will be ceased in October 2019.

In 2010 shut in bottom hole pressure is 2753 psia. So, as the reservoir pressure is declining, so new well NAR-3 will have low pressure support. The additional vertical well will have some initial improvement on total field production rate but would not last for longer time. From figure 7, when NAR-3 goes under production, plateau rate continued from January 2015 to July 2016 and then falls. NAR-3 will decline and meet the limiting condition before NAR-1 and NAR-2.

The Figure 8 shows that there is no significant change in field production total if one additional vertical well is added to LGS. From January 2015 to December 2017, the production will be faster but after that it will go down rapidly indicating very shorter plateau time than the existing condition.

Table 4: Lower Gas Sand Forecast Simulation Results THP 100psia.

\begin{tabular}{llllc}
\hline $\begin{array}{l}\text { Forecast } \\
\text { cases }\end{array}$ & $\begin{array}{l}\text { GIIP } \\
(\mathrm{BCF})\end{array}$ & $\begin{array}{l}\text { FGPT } \\
(\mathrm{BCF})\end{array}$ & $\begin{array}{l}\text { RF } \\
(\%)\end{array}$ & $\begin{array}{c}\text { Field life } \\
\text { (years) }\end{array}$ \\
\hline Case-1 & 302.72 & 204.02 & 67.40 & $\begin{array}{c}26 \\
(1996-2022) \\
23\end{array}$ \\
Case-2 & 302.72 & 203.98 & 67.38 & $\begin{array}{c}(1996-2019) \\
\end{array}$ \\
\hline
\end{tabular}

Table 4 describes the comparison of the results for case 1 and case 2 . The present situation gives recovery factor of $67.40 \%$ and the total production time will be 26 years, but adding one vertical well gives recovery factor and field life less than the current scenario.

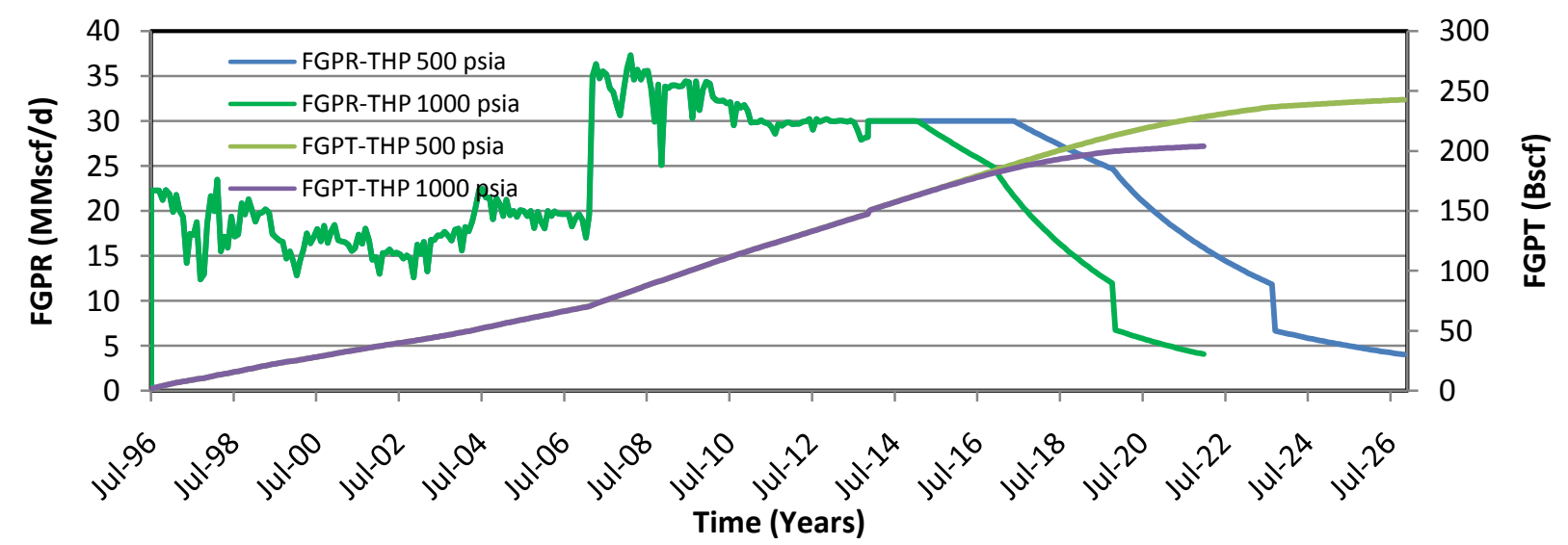

Figure 9: Impact of adding compressor on FGPR and FGPT for THP 1000 psia and 500 psia

Figure 9 shows that by installing compressors, total production will be 242.595 Bcf. Again in current situation, after 2015, the plateau will be diminished due to low bottomhole pressure, but adding compressor causes the increased production time for each of the wells and makes a little increase in field life from 26 years to 30 years and hence shifts the recovery factor significantly from $67.40 \%$ to $80.14 \%$. 


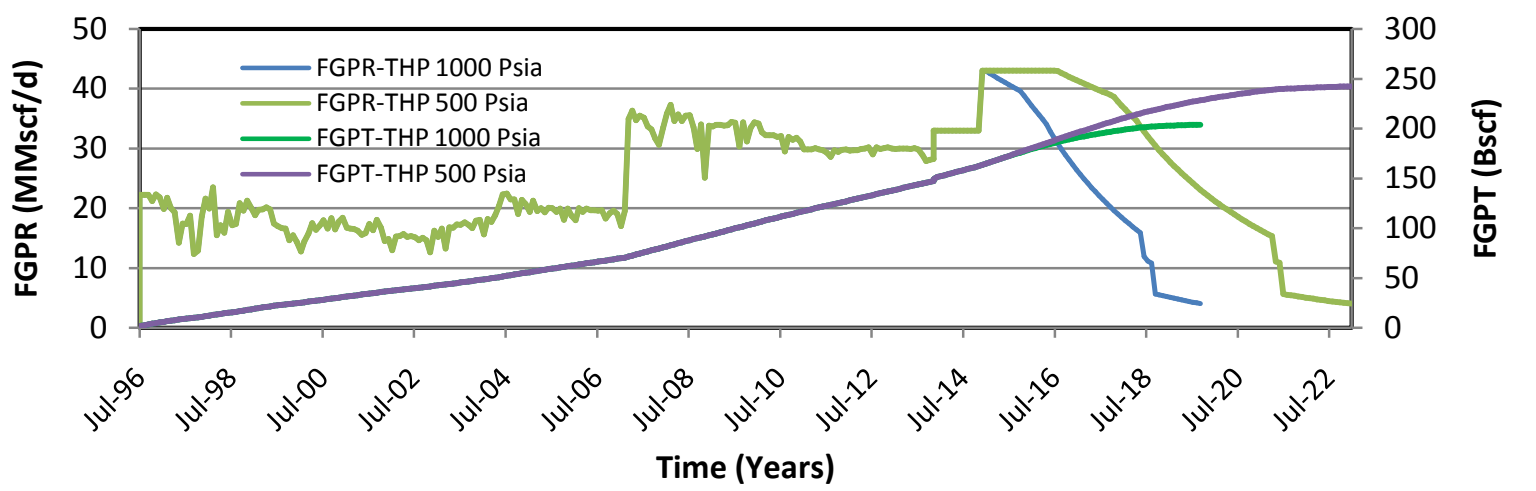

Figure 10: Impact of adding compressor on FGPR and FGPT for THP 1000 psia and 500 psia

Figure 10 shows the recovery factor of $80.09 \%$ which is same as seen in the forecast case 3 a shown in figure 9 and to attain the desired recovery, field life would be 27 years. Table 5 gives the summarized results of forecast case $3 a$ and $3 b$.

Table 5: Lower Gas Sand Forecast case 3 Simulation Results at $\mathrm{THP}=500$ psia

\begin{tabular}{lllll}
\hline $\begin{array}{l}\text { Forecast } \\
\text { cases }\end{array}$ & $\begin{array}{l}\text { GIIP } \\
(\mathrm{BCF})\end{array}$ & $\begin{array}{l}\text { FGPT } \\
(\mathrm{BCF})\end{array}$ & $\begin{array}{l}\text { RF } \\
(\%)\end{array}$ & $\begin{array}{l}\text { Field } \\
\text { life(Years) }\end{array}$ \\
\hline Case 3a & 302.72 & 242.60 & 80.14 & $\begin{array}{c}30 \\
(1996-2026) \\
27\end{array}$ \\
Case 3b & 302.72 & 242.46 & 80.09 & $\begin{array}{c}27 \\
(1996-2023)\end{array}$ \\
\hline
\end{tabular}

\section{Conclusions}

According to simulation model the GIIP is about 386.24 Bcf, where upper and lower gas sand contains 83.53 Bcf and $302.72 \mathrm{Bcf}$ respectively. This study shows that for existing condition, the use of compressor will increase the ultimate recovery from $67.40 \%$ to almost $80 \%$. Extra 4 years will be needed to achieve the recovery. In that case economic analysis about the installation of the compressor is required. Drilling one more vertical well in the lower gas sand will not be beneficial as it gives almost the same recovery of $67.38 \%$ as doing nothing case, though the recoverable reserve of $204 \mathrm{Bcf}$ could be attained earlier than 'Current Situation'. All the analysis done in this article does not include economic analysis. So, for field development, economic analysis for each of the forecast case is urgent. By doing this the optimum condition could be determined.

\section{References}

1. Gustafson Associates. 2011. Updated Report on Bangladesh Gas Reserve Estimation 2010, Hydrocarbon Unit, Energy and Mineral Resources Division, Government of the People's Republic of Bangladesh (February 15,2011).
2. Ikoku, C. U. 1984. Natural Gas Reservoir Engineering, the Pennsylvania University, Krieger publishing company Malabar, Florida

3. "Gas field appraisal project, Geological, geophysical and petrophysical report, Belabo Gas field, Bangladesh', Intercomp- Kanata Management Ltd (IKM) (1991).

4. "Well test report on Narshingdi gas field, well survey and testing section of development department' Bangladesh Gas Field Company Limited, 2007.

5. "Gas field appraisal project, Reservoir engineering report, Belabo Gas field, Bangladesh.' IntercompKanata Management Ltd (IKM) (1991).

6. "Narshingdi Reservoir Study Prepared for Petrobangla, Bangladesh." RPS Energy (September 2008).

7. "Production report on Narshingdi gas field" Bangladesh Gas Field Company Limited, 2008.

\section{Nomenclature}

FGPT : Field Gas Production Total

FGPR : Field Gas Production Rate

GIIP : Initially In Place

GIP : Gas In Place

GPR : Gas Production Rate

GPRH : Gas Production Rate History

MMscfd : Millions of Standard Cubic Feet per Day

FPR : Average Reservoir Pressure

THP : Tubing Head Pressure

THPH : Tubing Pressure History

WGPR : Well Gas Production Rate

WGPRH : Well Gas Production Rate History

WGR : Water-Gas-Ratio

SIWHP : Shut In Well Head Pressure

VFP : Vertical Flow Performance

MGS : Middle Gas Sand

RF : Recovery Factor

Bcf : Billion CUBIC feet 